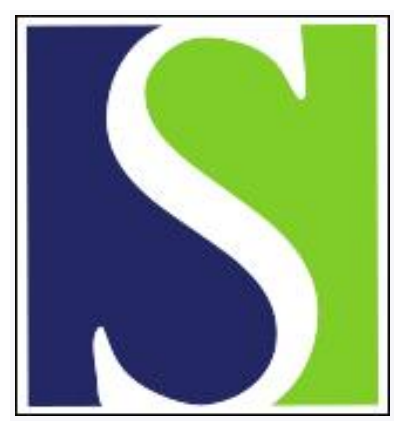

Scand J Work Environ Health 1981;7(2):141-151

https://doi.org/10.5271/sjweh.2555

Issue date: Jun 1981

Long-term adjustment of circadian rhythms to a rotating shiftwork schedule.

by Dahlgren $\mathrm{K}$

Key terms: body temperature; circadian rhythm; long-term adjustment; rotating shiftwork schedule; self-rated activation; shift work; shift work schedule; short-term adjustment

This article in PubMed: www.ncbi.nlm.nih.gov/pubmed/7313618

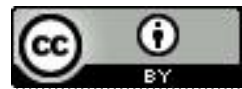




\title{
Long-term adjustment of circadian rhythms to a rotating shiftwork schedule
}

\author{
by Kerstin Dahlgren, $\mathrm{PhD}{ }^{1}$
}

\begin{abstract}
DAHLGREN K. Long-term adjustment of circadian rhythms to a rotating shiftwork schedule. Scand $j$ work environ health 7 (1981) 141-151. This investigation is a further study of the long-term effects of a weekly rotating day-night shift schedule on circadian rhythms. It was performed 3 a after the introduction of an increase in nighttime work. Six male typesetters were observed in connection with the beginning and end of the nightshift week and in connection with their free days in the "day week." Measurements were taken of body temperature during both the awake and sleep periods and of self-rated activation. For the same subjects a comparison was also made of variations in awake temperatures and self-rated activation after one month, one year and three years on the new shift schedule. Results showed that after 3 a of experience the awake temperature curves had a flattened shape in connection with both the beginning and end of the nightshift week and also during the free days. During sleep there was however a short-term adjustment of the temperature curves within the nightshift week. Comparisons over years revealed significant changes in the course of variation in body temperature during both night and day work, while no significant changes were found for self-rated activation. The possibility that experience has a differential influence upon the phase adjustment of temperature maxima compared to minima was discussed.
\end{abstract}

Key terms: body temperature, self-rated activation, short-term adjustment.

The present investigation is a further study of the long-term effects of a rotating shiftwork schedule on circadian rhythms. In two previous studies $(1,5)$ a group of rotating shift workers were studied with regard to the adjustment of circadian rhythms in physiological and psychological functions to their weekly alternation between night and day activity. The first of these studies was performed one month and the second $1 \mathrm{a}$ after workhours during the nightshift week had been changed to a schedule that involved more nighttime work.

The results of the first study indicated some short-term adjustment during the nightshift week with regard to variations in body temperature, self-rated activation,

1 Department of Psychology, University of Stockholm, Sweden.

Reprint requests to: Dr Kerstin Dahlgren, Department of Psychology, University of Stockholm, Box 6706, S-113 85 Stockholm, Sweden. and adrenaline excretion. This adjustment took the form of an increase in levels during night work from the beginning to the end of the nightshift week. One year later evidence of long-term adjustment in these functions was found in that a general flattening of the curves appeared on all days of the night week observed, although some changes during the week could also be seen. In addition, tendencies towards a flattening of curves were seen also in connection with the two dayshifts included in the schedule.

The present investigation is a further study of the long-term effects of the new shift schedule on circadian functions. Three years after the increase in nighttime work a smaller group of the same shift workers participated in a sleep study. The main purpose was to compare the adjustment of circadian rhythms and objective measures of sleep functions (electroencephalography) between these rotating shift workers and permanent night 
workers (4). In addition, the study provided an opportunity to observe the longterm adjustment of circadian variations in body temperature and self-rated activation after 3 a of experience with the new shift schedule. It was also possible to get a more complete picture of this long-term adjustment since observations also included the free days in the "day week" and the measurements of body temperature covered both the awake and sleep periods.

\section{Methods}

\section{Subjects and general design}

The subjects consisted of six male typesetters employed in the printing department of a large Swedish newspaper. The median age of the group was 41 a with a range of $33-59$ a. Their shift schedule consisted of seven consecutive nights of work between approximately 2230-0500, followed by one free day, two days of work between 0730 and 1630 and four free days. Thus, they alternated between a night-oriented and a day-oriented week, although the latter contained less actual work. At the time of the present study all the subjects had been working with this shift schedule for 3 a. Before that, their schedule contained less nighttime work during the nightshift week, with $5 \mathrm{~d}$ of work between 1830 and 0230 and $2 \mathrm{~d}$ between 2300 and 0700 . Their median experience with this schedule was 7 a, and none of them had any other previous experience with shift work that included night work.

The workers came to the sleep laboratory for a total of six sleeping periods, of which the first two served as adaptation.

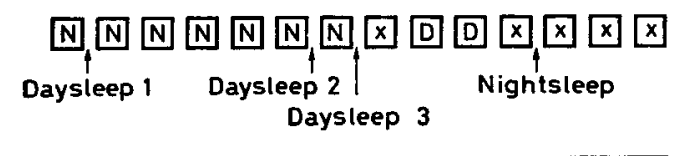

$\mathrm{N}=$ Night shift, $\mathrm{D}=$ Day shift, $\mathrm{x}=$ Free day

Fig 1. Design of the study. The observed awake periods preceding and following each observed sleep period were as follows: Day sleep 1 between nightshift 1 and 2, day sleep 2 between nightshift 6 and 7 , day sleep 3 between nightshift 7 and free day 1 , and night sleep between free day 2 and 3 , ie, the fourth and fifth day of the week.
Of interest in the present paper are the recordings of body temperature and selfrated activation obtained in connection with the observed sleep periods, as further described for each variable later in this paper. The observed sleep periods consisted of three day sleep periods after night work and one night sleep period during the free days (fig 1). The day sleep periods followed the first, sixth and seventh (last) nightshifts, whereas the night sleep period was after one of the free days - the fourth day of the day week. The order of the four sleep periods observed were balanced over four of the subjects and were according to the scheme in fig 1 for the other two subjects. All the workers arrived at the sleep laboratory at approximately the same time, and they were instructed to sleep as long as they usually did at home.

\section{Body temperature}

In a diary, the subjects recorded their oral temperature at $3-\mathrm{h}$ intervals during the awake time preceding and following each sleep period observed in the laboratory. In connection with night work these recordings were made when the subjects arose and at 1500, 1800, 2100, 2400,0300 and before they went to sleep, while during free days they were made when the subjects arose and at 0900, 1200, $1500,1800,2100$ and before they went to sleep. During sleep, rectal temperature was recorded continuously with a resistance thermometer, and readings were made at each clock hour during sleep.

\section{Self-rated activation}

The general activation factor, as translated from Thayer's (12) Activation-Deactivation Adjective Checklist, was used for rating alertness. Adjectives were rated from "not at all descriptive" to "completely descriptive," and the ratings were scored from one to four. The ratings were made simultaneously with the measures of oral temperature, and they were recorded in the diary kept by the subjects.

\section{Questionnaire}

A questionnaire was used to collect information on background data, sleep difficulties, sleep length, and diurnal type. 
Comparisons with the two previous studies

For five of the subjects who participated in the sleep study, complete data for variations in body temperature during awake periods and for self-rated activation were also available from the studies performed one month and $1 \mathrm{a}$ after the change in workhours during the nightshift week. A comparison of variations in body temperature and self-rated activation in the beginning and end of the nightshift week was therefore made after one month, $1 \mathrm{a}$ and $3 \mathrm{a}$ on the new schedule. A similar comparison was made also for one day in the week, although for the first two studies this represented the third day of the day week (second dayshift) and for the sleep study the fourth day of the day week.

Furthermore, questionnaire data on sleep difficulties and sleep length in connection with night and day work, as well as free days, were also available for all three studies except night sleep in the third study.

\section{Statistical methods}

For a determination of whether body temperature and self-rated activation exhibited a significant variation with time of day, the data were subjected to a onefactor analysis of variance for repeated measurements according to Winer (13). This analysis was performed separately for each day of measurement. Separate analyses were also made for body temperature variations during the awake and sleep periods, since the recordings were collected by different methods. Furthermore, for a determination of whether there were any significant changes in the adjustment of these circadian functions from the beginning to the end of the nightshift week, each parameter was also subjected to a two-factor analysis of variance with repeated measurements on both factors, ie, "time of day" and "days." In this analysis only the awake and sleep periods in connection with the first and last nightshifts were included.

It was also of interest to determine whether there were any significant

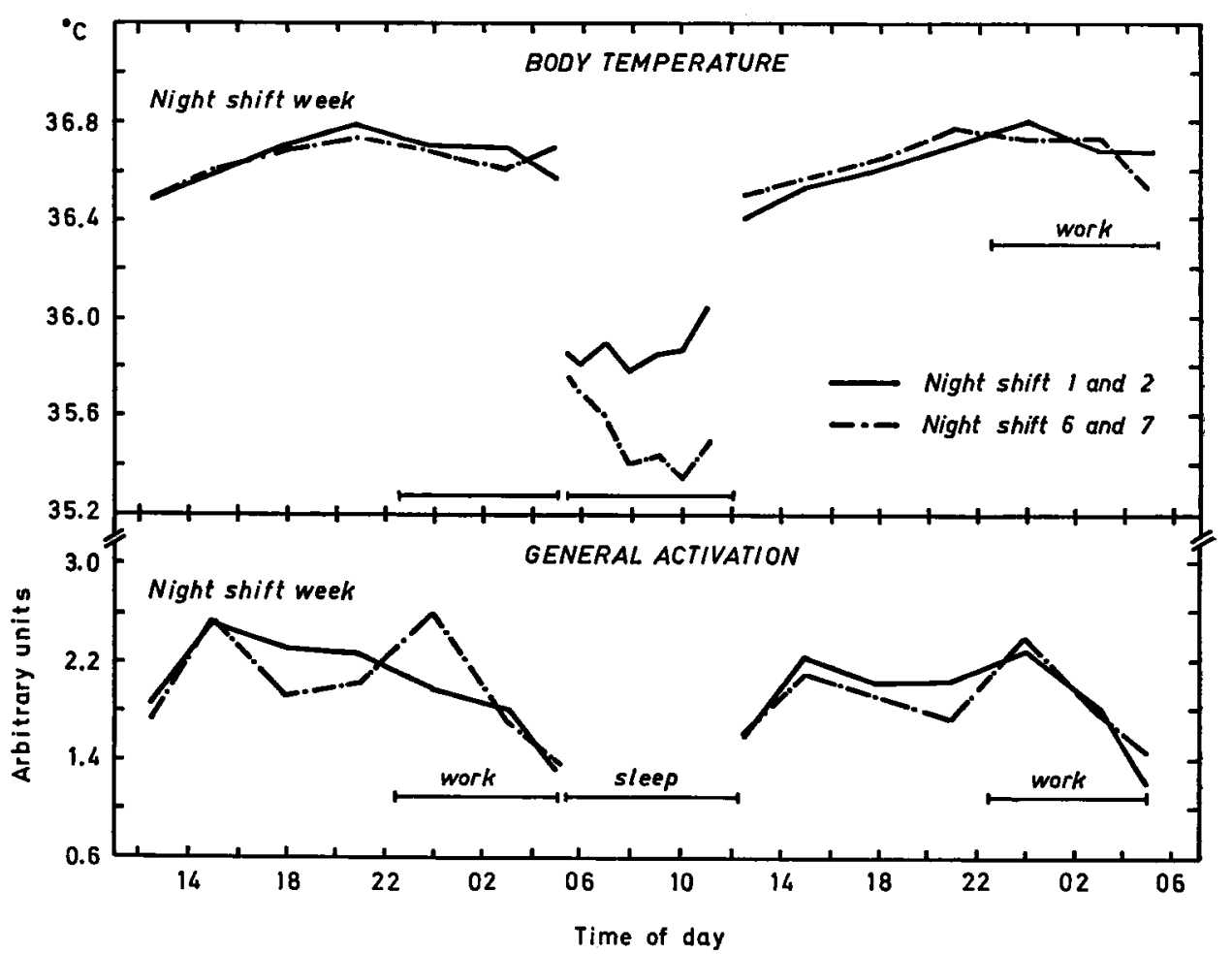

Fig 2. Average body temperatures (oral) and self-rated activation during the awake periods before and after each day sleep period observed and the average body temperatures (rectal) during each day sleep period in the beginning and end of the nightshift week. 
changes in the pattern of variation in body temperature and self-rated activation with increased experience with the new shift schedule. For this purpose a comparison was made between the first and third study for each variable on each day of measurement through a two-factor analysis of variance with repeated measurements on both factors, ie, "time of day" and "studies."

\section{Results}

The results from the present study are for the average variations in temperature and self-rated activation in connection with night work, illustrated in fig 2 , and for free days, fig 3 . The results of the one- and two-factor analyses of variances are presented in table 1.

\section{Body temperature}

During the nightshift week the pattern of variation was fairly similar for the awake periods. The curves had a flat shape, and the variation over time was significant only in connection with the last nightshift.
There were no significant changes in temperature variations from the first to the last nightshift. During sleep there were more marked differences between the average temperature curves in the beginning (day sleep 1) and the end (day sleep 2) of the nightshift week. The first day sleep period was characterized by a temperature curve with a flat shape and no significant variation over time. At the end of the week there was a significant variation characterized by a continuous decrease towards a minimum in the latter half of the sleep period. Compared to that of the first day sleep period, the average level was significantly lower at the end of the week, and the difference in the course of variation was supported by a significant interaction effect.

Because of the flattened shape of the average temperature curves during the awake periods, it was also of interest to inspect the pattern of the individual temperature curves. Illustrated in fig 4 are the individual temperature curves during the awake periods in connection with the first and last nightshifts and also the variations

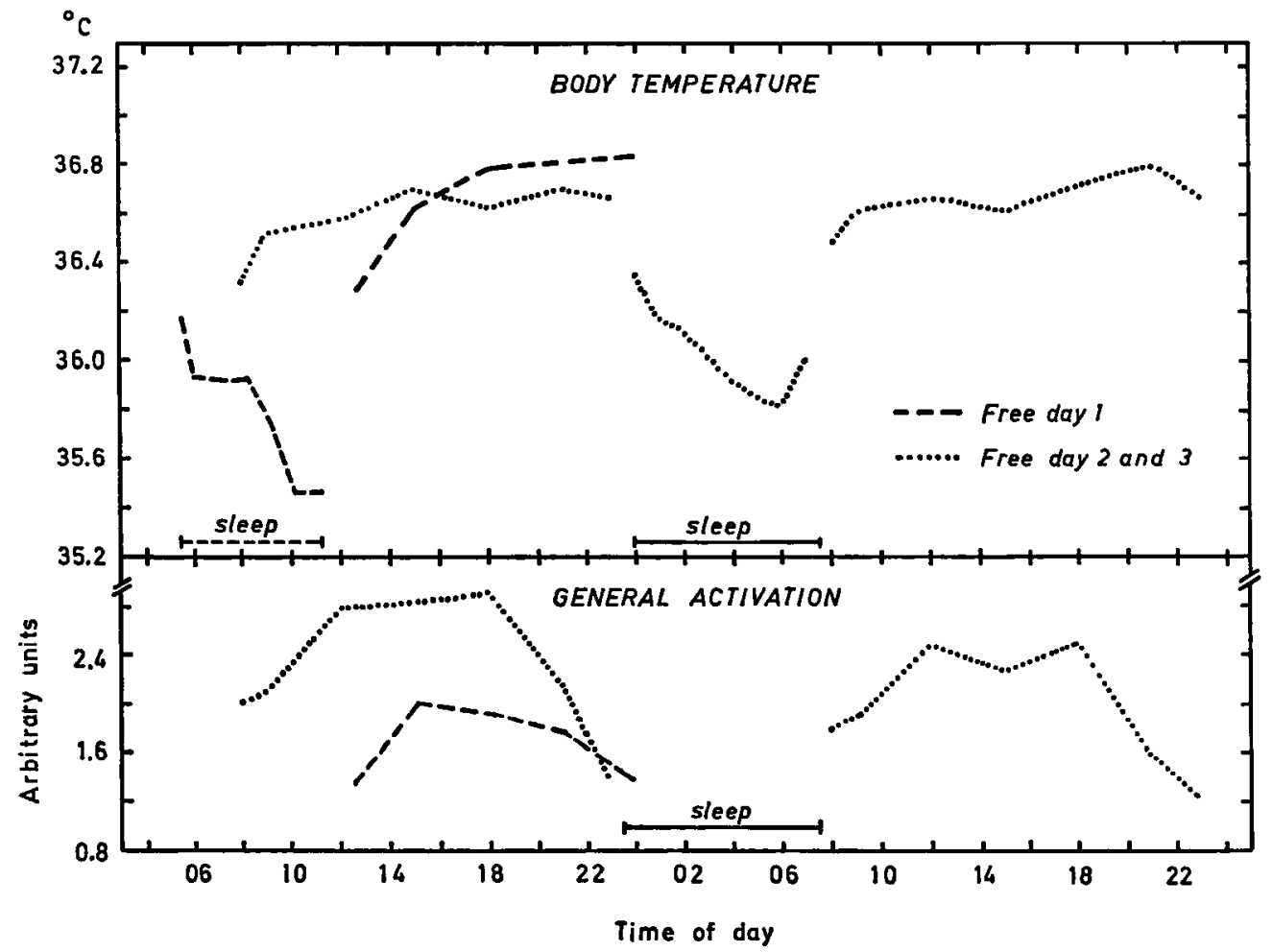

Fig 3. Average body temperatures (oral) and self-rated activation during the awake periods in connection with the free days and the average body temperatures (rectal) during the day sleep period after the last nightshift and during night sleep. 
during sleep after the first and before the last nightshift. A flattened shape in the awake temperature curves was representative of most of the subjects at both the beginning and end of the week, except for subject $\mathrm{C}$. Most subjects also showed a marked change in the pattern of variation during sleep from the beginning to the end of the week; this change was representative of the average temperature curves.

During the day sleep period after the last nightshift, ie, on the first free day (day sleep 3), the temperature varied significantly over time. The variations followed a pattern (fig 3) differing somewhat from the other day sleep periods, the relatively high levels in the first half of the sleep period decreasing rapidly towards the end of sleep. The temperature varied significantly also during the following awake period, increasing from relatively low levels upon awakening towards a plateau in the evening hours, with a maximum level similar to that found during night work. The awake temperatures during the other free days were both characterized by curves with a flat shape, although a significant variation was found for the fourth day of the day week (free day 2). The significant variations during night sleep showed a continuous decrease towards the end of sleep.

An inspection of the individual temperature curves in connection with free days (fig 5) also confirmed a flattened shape in the awake curves for most subjects. Although the variations during night sleep for most subjects showed the same tendency to decrease towards a minimum in the latter half of the sleep period, the average levels were on the whole, relatively high.

\section{Self-rated activation}

Significant variations with time of day were found for all the days observed (table 1). Activation in connection with the first nightshift was highest around 1500 and thereafter slowly decreased during the rest of the day and during night work. On the following day an additional peak appeared during work at 2400 after a decrease in the late afternoon. This pattern of variation was characteristic also of the days at the end of the nightshift week, albeit more accentuated. On the day following the last nightshift the highest levels were again reached at 1500 and followed by a slow decrease.

In connection with the free days, a relatively pronounced variation was found on the fourth day of the week, whereas the levels decreased somewhat during the following day.

\section{Long-term changes in adjustment}

The average body temperature curves from the three studies are illustrated in fig 6 , and the analyses of variances are presented in table 2.

In connection with the first nightshift a significant variation over time was found only for the first study, and it was

Table 1. Summary of one- and two-factor analyses of variances for repeated measurements of body temperature and self-rated activation. The one-factor analyses cover each awake and sleep period observed in connection with night work and free days. The two-factor analyses cover the awake and sleep periods in connection with the first and last nightshift.

\begin{tabular}{lccc}
\hline & $\begin{array}{c}\text { Body } \\
\text { temperature }\end{array}$ & $\begin{array}{c}\text { Self-rated } \\
\text { activation }\end{array}$ & \\
& F & F & df \\
\cline { 2 - 4 } & & & \\
One-factor analyses & & & \\
Nightshift 1 & 1.4 & $4.1^{* *}$ & $6 / 30$ \\
Nightshift 2 & 2.3 & $3.5^{* *}$ & $6 / 30$ \\
Nightshift 6 & 1.5 & $2.4^{*}$ & $6 / 30$ \\
Nightshift 7 & $2.5 *$ & $3.3^{* *}$ & $6 / 30$ \\
Free day 1 & $10.9 * * *$ & $3.8^{*}$ & $4 / 20$ \\
Free day 2 & $4.7^{* *}$ & $6.0^{* * *}$ & $6 / 30$ \\
Free day 3 & 1.8 & $6.4^{* * *}$ & $6 / 30$ \\
& & & \\
Day sleep 1 & 0.9 & & $6 / 30$ \\
Day sleep 2 & $4.6 * *$ & & $6 / 30$ \\
Day sleep 3 & $4.2 * *$ & & $6 / 30$ \\
Night sleep & $8.7 * * *$ & & $6 / 30$
\end{tabular}

Night sleep

Two-factor analyses

Nightshift 1 and 7

$\begin{array}{llll}\text { Time of day (T) } & 2.1 & 5.2^{* *} & 6 / 30 \\ \text { Between days (B) } & 0.1 & 1.2 & 1 / 5 \\ \text { Interaction (T } \times \text { B) } & 0.2 & 2.6^{*} & 6 / 30\end{array}$

Day sleep 1 and 2

Time of day (T) $3.3 * \quad 6 / 30$

Between days (B) $12.3^{*} \quad 1 / 5$

Interaction $(T \times B) \quad 3.5^{* *} \quad 6 / 30$

$* p<0.05, * * p<0.01, * * * p<0.001$. 


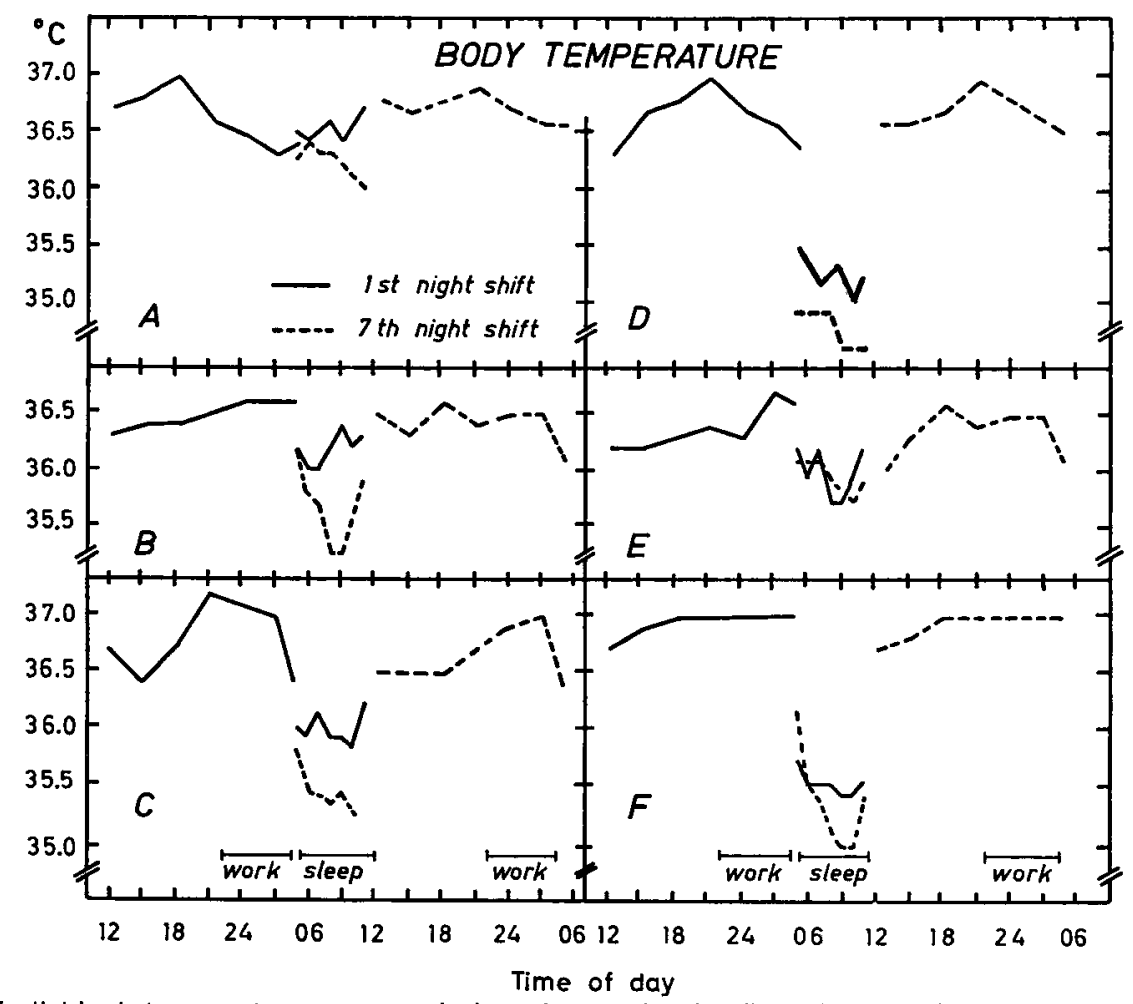

Fig 4. Individual temperature curves during the awake (oral) and sleep (rectal) periods in connection with the beginning and end of the nightshift week for subjects A-F.

characterized by a sharp increase towards a peak outside the workhours at 2000 followed by an equally sharp decrease during work. One year later the temperature levels were lower, and the curve lacked a more pronounced variation although a peak was still present outside the workhours at 2000. Three years later the mean level was still lower, and after a slow increase up to 2000 the temperature levels were fairly similar throughout the major parts of the work period.

In connection with the last nightshift a significant variation over time was again found only for the first study, but the peak was reached in the first part of the work period at 2400 . One year later the curve was flatter, but the highest level was also reached at 2400 . Three years later the average level was still lower when compared to that of the first study, and the pattern of variation was similar to that found in connection with the first nightshift.

For the days of the day week a significant variation over time was present in the first and third studies. While in the first study the variation was characterized by an increase towards a peak at about 1800 followed by a decrease before sleep, that of the second, and particularly the third, study was characterized by lower average levels and a slow increase during the whole awake period.

A significant change in the course of variation in temperature between the first and the third study was found for the last nightshift and the observed day in the day week (table 2).

The results for self-rated activation are illustrated in the lower part of fig 6 , and the analyses of variances are presented in table 2.

In connection with the first nightshift a significant variation over time was found for the first and third studies; it was characterized in both studies by peaks at around 1500 , followed by a slow decrease for the rest of the awake period. In the second study the variation was far from significant, and curves were characterized by fluctuations in activation.

In connection with the last nightshift a significant variation over time was again 
found only for the first and the third studies, and the pattern of variation was also similar, with a peak at 1500 followed by a decrease and a second peak at 2400 . In the second study there was no significant variation over time, the curve was flat, and the general level low.

For the days of the day week the variations in self-rated activation were not significant for the first study, but they were significant for the second study with the highest levels in the middle of the day and significant after $3 \mathrm{a}$ with peaks in the late afternoon.

There were no significant changes in the pattern of variation in self-rated activation between the first and the third studies for any of the days (table 2).

\section{Questionnaire}

Questionnaire answers regarding sleep difficulties and sleep length in connection with night work, day work, and free days are shown in table 3. "Sleep difficulties" consisted of their answers to several questions combined into one score, whereas "sleep length" was calculated from their estimated habitual times for falling asleep and waking up.

Though the number of subjects was too few to make a statistical test on this type of data relevant, it is interesting to note tendencies in the data. Longer experience with the shift schedule was accompanied by a tendency for sleep length to increase in connection with night work and to decrease in connection with day work. In addition sleep difficulties tended to decrease during day sleep and increase during night sleep. Complete data were, however, not available for night sleep in the third study.

\section{Discussion}

After 3 a of experience with the new shift schedule the body temperature

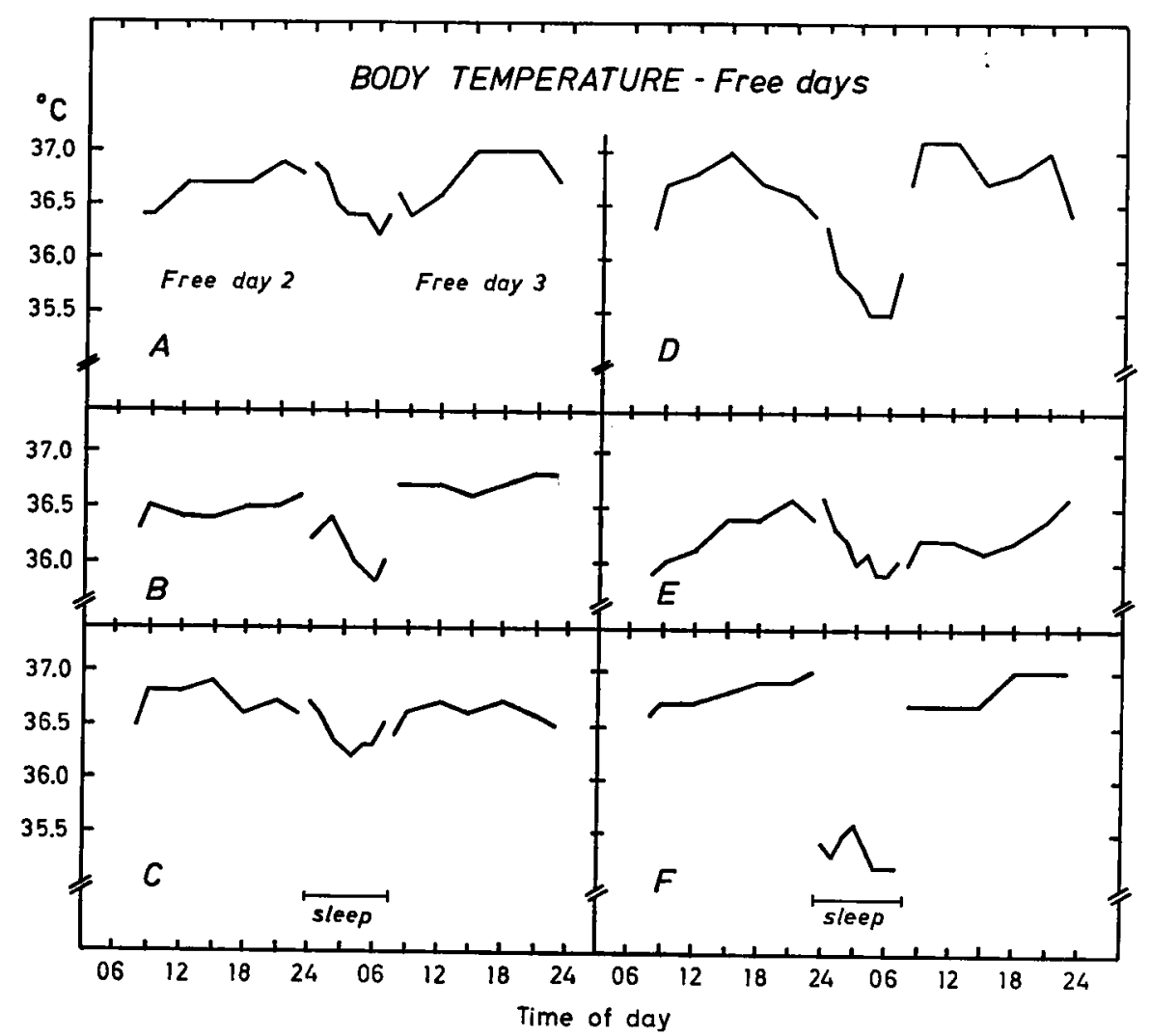

Fig 5. Individual temperature curves during the awake (oral) and sleep (rectal) periods in connection with the free days for subjects A-F. 


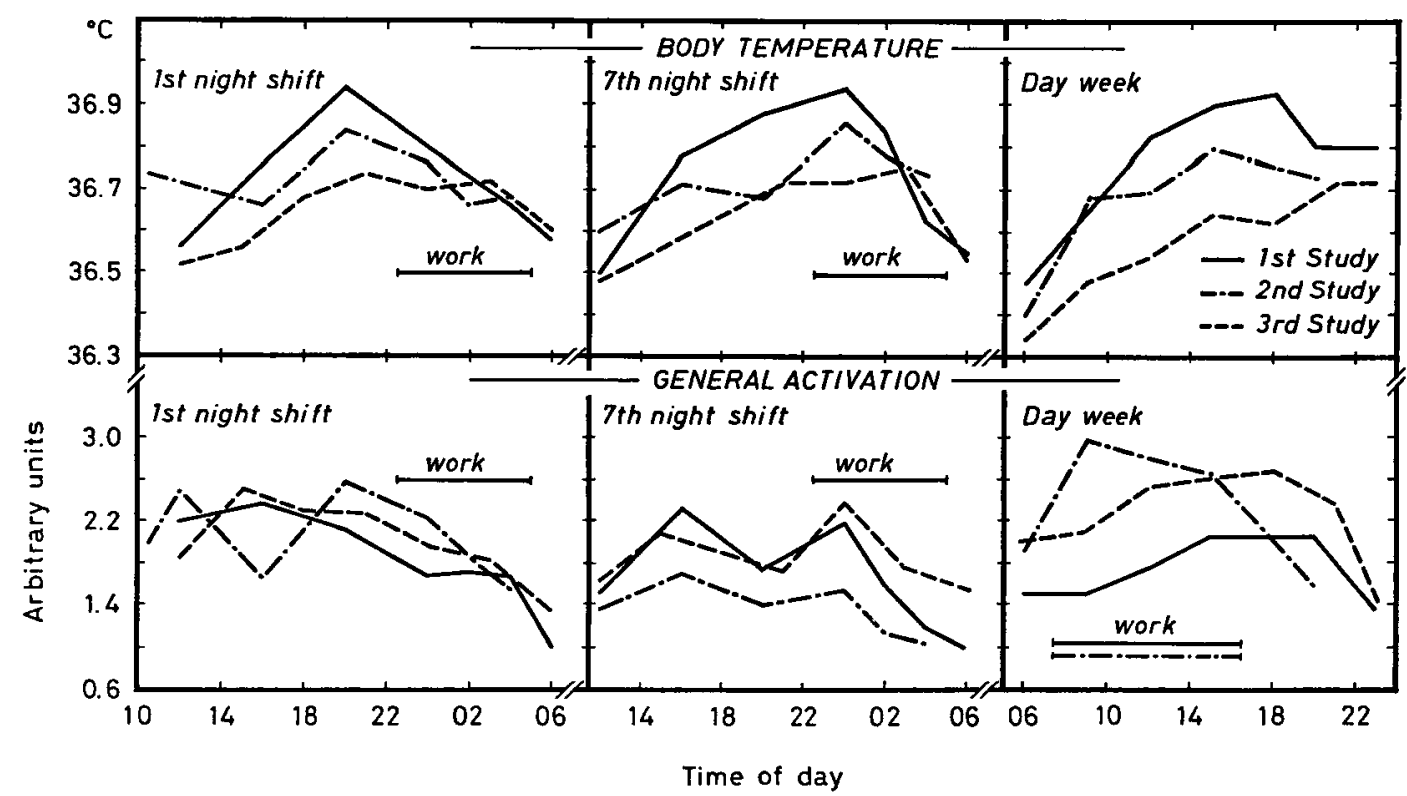

Fig 6. Average body temperatures and self-rated activation after one month (study 1), 1 a (study 2) and 3 a (study 3 ) on the new shift schedule.

curves during the subjects' awake periods exhibited a similar pattern of variation in the beginning and end of the nightshift week. This pattern was characterized by a flattened shape compared to that found among day workers [for example, in the study of Aschoff (2)]. A short-term adjustment during the week did, however, occur in the form of a change in the pattern of variations during sleep that suggested a phase shift of minima by the end of the week. These characteristics were also representative of most of the individual temperature curves. During free days the temperature curves also had a flattened shape. However, several of the individual temperature curves showed traces of a more night-oriented rhythm with relatively high levels at their usual hours for night work.

Comparing the awake temperature curves for the same subjects one month, $1 \mathrm{a}$ and $3 \mathrm{a}$ after the increase in nighttime work revealed a consistent change in the pattern of variation with increased experience. For the first and last nightshifts this long-term adjustment was characterized by a general flattening of the rhythm and a lowering of the mean level. Furthermore, while there was some short-term adjustment within the nightshift week after only one month's experi- ence, after 3 a the best possible adjustment seemed to occur already in connection with the first nightshift. However, this "partial adjustment" of the body temperature curve to night work was reflected in a change of the rhythm also during the day week. For the observed day a significant change in the course of variation, similar to that found for night work, appeared with increased experience.

While the long-term adjustment of the temperature rhythm during the awake periods was characterized by a general flattening of the curve within the nightshift week, this was not the case for the variations during sleep. Although a corresponding comparison over years was not available for the day sleep values, it is evident that even after 3 a of experience there was still a short-term adjustment of the curve within the nightshift week. When the shape of the average curves and the individual curves during sleep are considered, it appears as if they start adjustment anew in the beginning of the week, but on the other hand they reach a more complete phase shift of the minima in comparison to the maxima by the end of the week.

It is difficult to find similar studies of experienced shift workers to compare the results with, particularly studies with 
temperature measurements covering both the awake and sleep periods. However, a more marked phase shift of temperature minima than that of maxima after a phase shift in the activity cycle was found also in an experimental laboratory study of three consecutive weeks of night work $(7,8,9)$. The study was designed to resemble a real-life setting as much as possible. The greatest changes in the temperature rhythm took place within the first week of night work and were characterized by "flattening of amplitude, increase of amplitude, phase-shifting of minimum first to the early half of sleep, then to the 2nd half of sleep" (8). Upon a further analysis of the trends in the course of phase adjustment of the rhythm to night work, Knauth et al also concluded that "the change in the time of sleep seemed to influence the adaptation process more than the change in the time of work" (9). Thus, among these subjects without prior experience with night work and those in the present study with long experience with night work, there was a similar shortterm adjustment of temperature minima towards day sleep.

It may be that, in connection with night work, it is generally easier to phase-shift minima than maxima and that this phase shift will appear within a period of about one week of successive day sleep periods whether the person has much experience with night work or not. Among the present group of shift workers the results showed however that experience clearly influenced the pattern of variation during awake periods. Consequently the questions arise of (i) why it should be easier to phase-shift minima than maxima in connection with night work and (ii) why experience with night work or a particular shiftwork schedule should have greater influence upon the pattern of variation during awake than during sleep periods.

It seems necessary to make a more thorough analysis of the specific characteristics of the relation between the circadian system and the most important synchronizers of circadian rhythms connected with night work. Since in night work only the awake and sleep times are phase-shifted and the most important synchronizers
Table 2. Summary of one-factor (time of day effect) and two-factor (comparisons between studies 1 and 3) analyses of variances for repeated measurements of body temperature and self-rated activation in connection with the first and last night shift and one day in the "day week."

\begin{tabular}{cccc}
\hline & $\begin{array}{c}\text { Body } \\
\text { temperature }\end{array}$ & $\begin{array}{c}\text { Self-rated } \\
\text { activation }\end{array}$ & \\
& & $F$ & df \\
\cline { 3 - 4 } & & & \\
One-factor analyses & & & \\
Nightshift 1 & & & \\
Study 1 & $2.8 *$ & $3.8^{* *}$ & $5 / 20$ \\
Study 2 & 0.6 & 0.4 & $4 / 16$ \\
Study 3 & 1.2 & $4.7^{* *}$ & $5 / 20$ \\
Nightshift 7 & & & \\
Study 1 & $5.3^{* * *}$ & $3.2 *$ & $5 / 20$ \\
Study 2 & 1.1 & 2.2 & $4 / 16$ \\
Study 3 & 2.1 & $3.7 *$ & $5 / 20$ \\
Day shift & & & \\
Study 1 & $13.4 * * *$ & 1.1 & $6 / 24$ \\
Study 2 & 2.3 & $9.3 * *$ & $5 / 20$ \\
Study 3 & $6.1 * * *$ & $6.7 * * *$ & $6 / 24$
\end{tabular}

Two-factor analyses

Study 1 and 3

Nightshift 1

Between studies (S) 0.1

Interaction $(\mathrm{T} \times \mathrm{S}) \quad \mathbf{1 . 1}$

$6.4 * * * \quad 5 / 20$

$0.5 \quad 1 / 4$

$1.2 \quad 5 / 20$

Nightshift 7

Time of day (T) $4.1^{* *} \quad 5.7^{* *} \quad 5 / 20$

$\begin{array}{llll}\text { Between studies (S) } & 1.0 & 0.2 & 1 / 4\end{array}$

Interaction $\left(\mathrm{T} \times \mathrm{S}\right.$ ) $4.5^{* *} \quad 0.5 \quad 5 / 20$

Dayshift

Time of day (T) $8.6 * * * \quad 8.6 * * * \quad 5 / 20$

Between studies (S) $2.8 \quad 2.1 \quad 1 / 4$

Interaction $(T \times S) \quad 6.7^{* * *} \quad 1.3 \quad 5 / 20$

$* p<0.05, * * p<0.01, * * * p<0.001$

Table 3. Average sleep length and sleep difficulties (composite scores) reported in connection with the night- or dayshift and free days in each study - Results from the questionnaire.

\begin{tabular}{lccc}
\hline & Study 1 & Study 2 & Study 3 \\
\cline { 2 - 4 } & & & \\
Sleep length (h) & & & \\
$\quad$ Nightshift & 5.7 & 6.0 & 6.8 \\
Dayshift & 8.0 & 7.6 & 7.2 \\
Free days & 9.2 & 8.7 & 9.1 \\
Sleep difficulties & & & \\
Nightshift & 10.6 & 10.4 & 9.0 \\
Dayshift & 10.4 & 11.0 & - \\
Free days & 9.8 & 9.4 & 9.4 \\
\hline
\end{tabular}


remain intact, the circadian system is under the influence of conflicting synchronizers. This situation in turn renders a complete adjustment of endogenous circadian rhythms more difficult when compared to the phase shift required, eg, after a time-zone shift, during which all important synchronizers are shifted according to the desired rhythm. In such a case complete adjustment develops within about a week (6). Could it be that the specific influence from conflicting synchronizers involved in night work has a differential impact upon the phase adjustment of the body temperature rhythm during awake periods compared to sleep? When the facts that the most important synchronizers for man are social contacts and the awareness of time of day are considered, it seems at least reasonable to assume that during sleep these are of minor importance and that therefore the phase adjustment of minima may proceed further than is possible for maxima given a sufficient number of successive day sleep periods.

With regard to the pattern of variation during awake periods there was a general flattening of the rhythm among the present group of shift workers during both the nightshift week and the day week with increased experience. A tentative interpretation may be that with increased experience there is a change in the psychological meaning of the most important synchronizers. For this group of shift workers, with an equal amount of day and night activity and even more days of actual work during the night than during the day, nighttime may become more and more associated with work and eventually regarded as a less "odd" time for work, particularly compared to the experience of subjects working at night for the first time. Similarly, with the dominance of work at night, work during the day may become more "odd" than it is for permanent day workers. Also with regard to the other important synchronizers "social contacts," these shift workers had several workmates on the shopfloor, and the group cohesion among them also seemed to be quite strong. Thus the influence of conflicting synchronizers should, with increased experience, decrease somewhat in strength and may therefore facilitate a more rapid establishment of the "definite" nightshift curve within a period of successive nightshifts. That this group of shift workers showed a general flattening of the rhythm during both night and day work may be seen as a consequence of the particular shift schedule with demands on both day- and nightoriented activity. For workers on a permanent night work schedule a more complete adjustment of the body temperature rhythm to night work has been found ( 4 , 10).

The results for self-rated activation differed in some respects from those found for body temperature. After 3 a of experience there was a significant variation in alertness during all the days observed. However, in connection with night work, the variation was less pronounced, and the pattern of variation also differed from that found with the same method among day active subjects (12) or permanent morning (3) and permanent night $(4,10)$ workers. There was also a significant change in the pattern of variation from the beginning to the end of the nightshift week. From a somewhat flattened, but more day-oriented variation in connection with the first night shift, the curves during the following days showed a second peak at around 2400 that suggested some adjustment to night work. It is, however, doubtful whether this change represented a true phase shift of the rhythm. The dip in alertness in the late afternoon hours occurred close to the time for naps taken by all the subjects (4). Taub et al (11) found a significant increase in self-rated activation after naps among habitual nappers, while no change in oral temperature was noticed. It is thus possible that the second peak in alertness was more an effect of the naps than a reflection of a more basic change in circadian rhythm. The tendency for all the subjects to take naps appeared after the first night shift, which, according to the electroencephalographic measurements (4), probably was an effect of the disturbed and shortened first day sleep period. Thus measures of self-rated activation in connection with night work are probably sensitive indicators of both circadian variations and sleep deprivation effects. 
Increased experience with the new shift schedule did not significantly alter the pattern of variation in alertness. With regard to night work this lack of change may be understood in terms of the influence of sleep deprivation upon self-rated activation. The first day sleep period within the nightshift week was, even after 3 a of experience, associated with an incomplete adjustment of the body temperature rhythm and disturbed sleep functions, which in turn probably also maintained the bimodal shape in the curve for self-rated activation on the following days.

In conclusion, the results of this study show that it is possible to develop longterm adjustment of the body temperature rhythm to a rotating shiftwork schedule. However, this long-term adjustment seems to develop over a relatively long period; in the present case more than $1 \mathrm{a}$ was required. Furthermore, experience seems to influence the adjustment during awake periods more than during sleep. Thus, for a more complete picture of any long-term adjustment to a particular shift schedule, consideration of the adjustment during both the awake and sleep periods and also over a sufficient length of time is important. The characteristics of the longterm adjustment achieved are probably related to the type of shiftwork schedule worked, particularly with regard to the number of successive nightshifts and also the amount of night work in relation to day work. With the present schedule the long-term adjustment during the awake periods represented an incomplete adjustment to both day and night activity.

\section{Acknowledgment}

This study was supported by grants from the Swedish Work and Environment Fund.

The author would like to express her gratitude to the subjects who participated in this study and to Prof P Pátkai for her valuable advice and encouragement.

\section{References}

1. Åkerstedt T, Pátkai $\mathrm{P}$, Dahlgren K. Field studies of shift work: II. Temporal patterns in psychophysiological activation in workers alternating between night and day work. Ergonomics 20 (1977) 621-631.

2. Aschoff J. Der tagesgang der Körpertemperatur beim Menschen. Klin Wochenschr 33 (1955) $545-551$.

3. Dahlgren $K$. Biologische Tagesrhythmen bei unterschiedlicher Anordnung der Arbeitzeit. In: Hildebrandt $G$, ed. Biologische Rhythmen und Arbeit. Springer-Verlag, Vienna-New York 1976, pp 97-107.

4. Dahlgren $K$. Adjustment of circadian rhythms and FEG sleep functions to day and night sleep among permanent night workers and rotating shiftworkers. Psychophysiology (in press).

5. Dahlgren $K$. Temporal patterns in psychophysiological activation in rotating shift workers - A follow-up field study one year after an increase in nighttime work. Scand $j$ work environ health 7 (1981) $131-140$.

6. Klein KE, Wegmann HM, Hunt B. Desynchronisation of body temperature and performance circadian rhythm as a result of outgoing and homegoing transmeridian flight. Aerosp med 43 (1972) 119-132.

7. Knauth $\mathbf{P}$, Ilmarinen J. Continuous measurement of body temperature during a three-week experiment with inverted working and sleeping hours. In: Cloquhoun P, Folkard S, Knauth P, Rutenfranz J, ed. Experimental studies of shiftwork. Westdeutscher verlag, Opladen 1975, pp 66-73.

8. Knauth P, Rutenfranz J. Experimental shiftwork studies of permanent night, and rapidly rotating, shift systems: I. Circadian rhythms of body temperature and reentrainment at shift change. Int arch occup environ health 37 (1976) 125-137.

9. Knauth P, Rutenfranz J, Herrmann G, Poeppl SJ. Re-entrainment of body temperature in experimental shiftwork studies. Ergonomics 21 (1978) 775-783.

10. Pátkai P, Ảkerstedt T, Pettersson-Dahlgren K. Field studies of shiftwork: I. Temporal patterns in psychophysiological activation in permanent night workers. Ergonomics 20 (1977) 611-619.

11. Taub JM, Tanguay PE, Clarkson D. Effects of day-time naps on performance and mood in a college student population. J abnorm psychol 85 (1976) 210-217.

12. Thayer $R$. Measurement of activation through self-report. Psychol rep 20 (1967)
$663-678$.

13. Winer BJ. Statistical principles in experimental design. 2nd ed. Mc-Graw-Hill, New York, NY 1971. 